\title{
Predictive Relationship Between Health System Attributes and Access to Essential Maternal and Child Health Services: Evidence from a SARA Survey
}

\author{
Dr. Alhassan Fouard Kanu (FRSPH) \\ Country Progamme Manager \\ Maintains -Sierra Leone
}

\begin{abstract}
The robustness and responsiveness of a country's health system predict access to a range of health services, including maternal and child health $(\mathrm{MCH})$ services. The purpose of this cross-sectional study was to examine the influence of 5 health system characteristics on access to MCH services in Sierra Leone. The study was a secondary analysis of the Sierra Leone 2017 Service Availability and Readiness Assessment (SARA) dataset, which comprised $100 \%(1,284)$ of the country's health facilities. Data analysis included bivariate and multivariate logistic regressions. In the bivariate analysis, all the independent variables showed statistically significant association with access to $\mathrm{MCH}$ services and achieved a $p$-value $<.001$. In the multivariate analysis; however, only 3 predictors explained $38 \%$ of the variance $\left(R^{2}=.380, F(5,1263)=154.667, p<.001\right)$. The type of health provider significantly predicted access to $\mathrm{MCH}$ services $(\beta=.549, p<.001)$, as did the availability of essential medicines $(\beta=.255, p<.001)$ and the availability of basic equipment $(\beta=.258, p<.001)$. According to the study findings, the availability of the right mix of health providers, essential medicines, and basic equipment significantly influenced access to $\mathrm{MCH}$ services, regardless of the level and type of health facility. The findings of this study might contribute in helping the authorities of the Sierra Leone health sector to identify critical health system considerations for increased access to $\mathrm{MCH}$ services and improved maternal and child health outcomes.
\end{abstract}

Keywords: health system, health services, maternal health, child health, healthcare access

DOI: $10.7176 / \mathrm{JHMN} / 76-06$

Publication date:June 30th 2020

\section{Introduction}

There have been sustained global efforts in the past 2 decades to address maternal and child health issues. These issues are disproportionately impacting low- and middle-income countries (LMIC) in terms of morbidities, mortalities, and economic burden. In 2000, the World Health Organization (WHO, 2011a) issued the Abuja Declaration that galvanized the commitment of 189 nations towards the improvement of social and economic conditions of the poorest countries in the world by 2015. The Abuja Declaration had the potential of positively impacting the lives of vulnerable women and children as they suffer the most from the consequences of social and economic deprivations. The Millennium Development Goals (MDGs) are an elaboration of the Abuja Declaration as they also required wealthy nations to provide resources for improvement, and the poor developing countries themselves to implement and maintain appropriate efforts towards the attainment of the goals. Goals 4 and 5 aimed at reducing child mortality and improving maternal health; and poor maternal and child health outcomes are some of the burdensome issues in poorer nations (WHO, 2011b). The Sustainable Development Goals (SDG) agenda also highlighted the importance of continued efforts towards improving maternal and newborn health. Under the SDG Goal 3, maternal mortality ratio (MMR) of fewer than 70 deaths per 100,000 live births was set, and aiming for all countries to reduce neonatal mortality to 12 per 1,000 live births by 2030 (United Nations[UN], 2016).

A significant improvement in maternal and child survival was observed since the adoption of the MDGs. The MDG 2015 report showed a worldwide drop by 45\% of MMR between 1990 and 2013, from 380 maternal deaths per 100,000 live births to 210 (UN, 2015). A decline of $49 \%$ of MMR was observed in sub-Saharan Africa (UN, 2015). Despite the progress, hundreds of deaths of women due to pregnancy and childbirth-related complications are estimated to occur every day, with most of these deaths disproportionately occurring in sub-Saharan Africa. Of the estimated 289,000 global maternal deaths that were reported in 2013,86\% of them occurred in sub-Saharan Africa and Southern Asia (WHO, 2014a; UN, 2015). The UN (2015) MDG report also showed a decline in child mortality rates, dropping from 90 to 43 deaths per 1,000 live births between 1990 and 2015. A significant decline was reported in sub-Saharan Africa; a drop from 179 deaths per 1,000 live births in 1990 to 86 in 2015 (UN, 2015). The MDG 2015 report, however, noted that, not only does sub-Saharan Africa carry about half of the burden of the world's under-5 deaths (an estimated 3 million in 2015), but it is also the region where both the number of live births and under-5 populations are expected to rise substantially over the next decades (UN, 2015). Under-5 deaths will increase unless progress in reducing the under-5 mortality rate is enough to outpace population growth. Sierra Leone, one of the poorest countries in sub-Saharan Africa, has one of the highest maternal and child mortality rates in the world, currently reported at 1,165/100,000 and 156/1,000, respectively (Demographic Health Survey 
[DHS], 2013). As reported by WHO (2014), over a lifetime, there is an approximately 5\% chance of a Sierra Leonean woman dying from childbirth and pregnancy-related causes. The country poor maternal and child health outcomes can be attributed to many factors, including poverty and civil unrest. The country had a 10-year civil war between 1991 and 2002, and this caused damages to health infrastructure (MoHS, 2015). By the end of the war in 2002 , only $16 \%$ of previous health facilities were operational, and most of them are within the capital city (Bertone, Samai, Edem-Hotah, \& Witter, 2014). Postwar reconstruction saw the rehabilitation and establishment of new health facilities coupled with health sector governance strengthening. In line with the global efforts to reduce the mortality rates of the vulnerable women and children through the MDG, the government of Sierra Leone introduced the Free Health Care Initiative (FHCI) in 2010. The initiative exempted pregnant women, lactating mothers, and under-5 children from paying for both preventive and curative services in all public health facilities (Government of Sierra Leone [GoSL], 2013). The introduction of the FHCI was seen as a catalyst for the start of the large-scale rebuilding of the healthcare system. There were a significant donor and multilateral support to strengthen the health system through health infrastructural expansion, improvement in drugs and medical supplies, and health worker capacity building. An evaluation report on the impact of the FHCI showed a significant uptake of both preventive and curative maternal and child health services between the period 2010 and 2015 (Witter et al., 2018).

Before the 2014 Ebola viral disease (EVD) outbreak in Sierra Leone, the health sector had made significant progress in some MDG indicators related to health. The country had seen improvement in health coverage, including (a) an increase from $7 \%$ to $16 \%$ in modern contraception; (b) skilled birth attendance improving from $42 \%$ to $62 \%$; (c) insecticide-treated bednets increase from $26 \%$ to $49 \%$; and (d) malaria treatment jumped from $6 \%$ to $77 \%$; diarrhoea management improving from $68 \%$ to $88 \%$, and basic immunization increasing from $54 \%$ to 78\% (DHS, 2013; Sierra Leone Ministry of Health \& Sanitation [MoHS], 2015). The relative gains of the FHCI scheme on maternal and child health were reversed by the Ebola epidemic and ultimately made it impossible to achieve any of the health-related MDGs (Ribacke et al., 2016). Like in postwar health sector reconstruction, the post EVD also witnessed an investment to strengthen the health system. This was as a result of the evidence of weak health sector governance and infrastructure that was blamed for the rapid spread of the epidemic (Ribacke et al., 2016; Elston et al., 2015). Scholars have indicated that individual and household characteristics such as poverty, illiteracy, religion, and cultural factors account for the poor maternal and child health outcomes (Stekelenburg et al., 2004; Tlebere et al., 2007). Although both preventable maternal and child mortalities are linked to the availability of resources at health facilities (Thaddeus \& Maine, 1994), the relationship has not been quantifiably examined in Sierra Leone. There is limited local knowledge on the extent to which the health system influences access to maternal and child healthcare $(\mathrm{MCH})$; particularly following the post-Ebola health sector investment to improve access to essential healthcare services for the vulnerable women and children. This study will provide empirical evidence on the health system influence on access to essential MCH services in Sierra Leone. The findings will contribute to efforts towards increasing access to quality MCH services in Sierra Leone. Further, the evidence generated from this study will provide insight into the role of the respective health system pillars on increasing access to healthcare and guiding health system investment. This is critical in maximizing gains from the shrinking support towards public health programs.

\subsection{An overview of healthcare service delivery in Sierra Leone}

Sierra Leone, a country of an estimated seven million people is situated in West Africa. Health services in the country are provided at three levels of care namely: the community (peripheral health units), district (secondary hospitals), and national (tertiary/referral hospitals).

The peripheral health units (PHU) are the first line of primary care and are further sub-classified into three levels, with MCH services provided at all these levels including at the secondary and tertiary hospitals:

Maternal and Child Health Posts (MCHP) are found below the hierarchy of healthcare delivery in Sierra Leone. These facilities are structured to cater for a population less than 5,000 and are located at the village level.

Community Health Posts (CHP) follow the MCHP in the hierarchy of healthcare delivery in Sierra Leone with the responsibility to provide health services to a population ranging between 5,000 and 10,000. The facilities are being managed by either a Community Health Assistant (CHA) or State enrolled community health nurse $(\mathrm{SECHN})$.

Community Health Centres (CHC): At the top of the community-level care table is the CHC. These facilities are situated at chiefdom level to provide health services to a population of 10,000-20,000 people. The staff of these facilities includes all the other staff that operates at the MCHP and CHP. It is manned by a community Health Officer (CHO) who has more advanced training in both preventive and clinical medicine. The head of the $\mathrm{CHC}$ supervisees staff of the MCHP and CHP.

\subsection{Methodology \\ 2.1 Data source}


This was a quantitative, secondary data analysis using cross-sectional survey data. The study's main purpose was to investigate the influence of health system factors on access to $\mathrm{MCH}$ services. The main source of this study was the Sierra Leone Ministry of Health \& Sanitation (MoHS) 2017 service availability an readiness asssessement (SARA). The WHO SARA methodology provides a comprehensive approach for monitoring the supply of health services using a standard set of tracer items to determine the extent to which health facilities are prepared or ready for the provision of services. The SARA questionnaires comprise of a range of measures on health system characteristics. Information on health system characteristics that were considered in the study encompassed the level of healthcare delivery, type of health facility (private vs. public), type of health provider, availability of essential medicines, and availability of basic equipment. The data were analyzed to understand the relative influence of health system characteristics on access to $\mathrm{MCH}$ services.

\subsection{Sampling and sampling procedure}

The sampling unit was the health facility as used in the 2017 SARA survey. A probability sampling design was used to draw a representative subset of health facilities that were assessed in the 2017 SARA survey. G*Power 3.1.9.2 software was used to calculate the sample size for statistical power of .80, alpha error $(\alpha)$ of .05. The effect size reported in the literature ranged from $O R=1.57(95 \% C I: 1.09-2.28)$ for the type of health facility and ANC availability (Tran, Gottvall, Nguyen, Ascher, \& Petzold, 2012) to $O R=4.9$ (95\% CI: 3.0-8.1) for the number of ANC interventions provided to pregnant women (Trinh, Dibley, \& Byles, 2007). A conservative effect size of 1.5 was chosen and estimated a sample size of 1,074 health facilities. The original 2017 SARA dataset had a total of 1,284 health facilities, and $100 \%$ of the dataset was used.

\subsection{Data collection methods}

The Sierra Leone 2017 SARA was conducted as a census of health facilities (both public and private health facilities), and this took place between March 2017 and April 2017. The default for the inclusion of health facilities in the census was the master facility list (MFL) that comprised of 1,284 health facilities All of the 1,284 health facilities in MFL were included in the study. WHO's SARA questionnaires, version 2017, were customized for Sierra Leone. Adaptation of the questionnaires was done during a three-day workshop using a consultative process to ensure that country-specific needs were included. The questionnaire was customized in CSPro, and the computer-assisted personal interviewing (CAPI) tool was configured on the tablet computers used for all data collection. Field enumerators and supervisors were trained at a 10-day workshop. A total of 21 pairs of enumerators collected the data, with each pair responsible for 56 health facilities during the period of the survey. The enumerators' time spent in each of the health facilities varies. On average, 1 day is spent in PHUs (CHC,CHP,MCHP) and 2-3 days in hospitals and clinics.An average of 39 days was spent by the teams to complete the data collection. Data collection was done through facility staff interviews, facility document reviews, and observations inorder to verify the presence of valid or functioning reported services and supplies.

\subsection{Measurement variables}

This study examined the nature of the association between health system characteristics (the independent variables) and access to essential MCH services (the dependent variable). The following health system characteristics (independent variables) were investigated: (a) types of health provider, (b) level of health facility, (c) availability of essential medicines, (d) availability of basic equipment, and (e) type of health facility (private vs. public). The dependent variable was "access to essential MCH services". A description and measurement of the variables are provided as follows:

Dependent variable: This is "access to $\mathrm{MCH}$ services", and this refers to the number of MCH services offered by the facility. This was measured based on the availability and functioning of supportive items categorized into three domains as follows: MCH service provider, essential medicines, and basic equipment. The following interventions and diagnostic procedures were measured: weight measurement, blood pressure measurement, blood test, urine test, HIV counseling and testing, iron supplementation, deworming, malaria prevention and treatment, tetanus toxoid, deliveries, postnatal care, childhood immunization, GMP, infant, and IYCF. These items are the minimum required at the basic health facility in Sierra Leone. Items that best represent the outcome variable are combined to form a composite dichotomous variable. $\mathrm{MCH}$ services availability score for each facility was calculated by adding the proportions. Facilities that score $50 \%$ or more are considered to have good access to $\mathrm{MCH}$ services, while those that score less than $50 \%$ are considered to have poor access to MCH services. This cut-off point of 50\% was also used in previous studies (Bintabara \& Mpondo, 2018; Bintabara, Nakamura, \& Seino, 2017). Independent Variables: These are the health system characteristics that can influence access to $\mathrm{MCH}$ services. Five health system attributes were considered in this study: (1) type of MCH service provider, (2) level of health facility, (3) type of health facility (4) availability of essential medicines, (5) availability of basic equipment.

Type of health provider: The professional category of the health provider coded as $1=$ Nurses and midwives; $2=$ doctors; $3=$ others $(\mathrm{CHO}, \mathrm{CHA})$ 
Level of health facility: This refers to the level of the health facility. Facility level is coded as: $1=\mathrm{MCHP} ; 2=\mathrm{CHP}$; $3=\mathrm{CHC} ; 4=$ hospital $5=$ Clinic

Type of health facility: This refers to facility ownership. It is coded as $1=$ public and $0=$ private

Availability of essential medicines. This refers to the type of essential medicines that are expected to be available at the basic MCH facility as prescribed by the country's basic package of essential health services (BPEHS) for delivery, newborn, and child care. The following drugs were considered for this variable: injectable antibiotic, injectable uterotonic, injectable magnesium sulfate, injectable diazepam, intravenous fluids, skin disinfectant, antibiotic eye ointment, 4\% chlorhexidine, injectable gentamicin, amoxicillin suspension, antimalaria, and analgesics. Essential medicines availability score for each facility is calculated by adding the proportions. Facilities that score $50 \%$ or more are considered to have good availability of essential medicines; while those that score less than $50 \%$ are considered to have poor availability of essential medicines.

Availability of basic equipment. This refers to the types of basic equipment available at the basic health facility as guided by the BPEHS. The following basic equipment was considered for this variable: sterilization equipment, sphygmomanometer, stethoscope, thermometer, child weighing scale, adult weighing scale, height board, MUAC, examination light, delivery pack, suction apparatus, manual vacuum extractor, vacuum aspirator or D\&C kit, neonatal bag and mask, and delivery bed. Basic equipment availability score for each facility is calculated by adding the proportions. Facilities that score $50 \%$ or more are considered to have good availability of basic equipment; while those that score less than $50 \%$ are considered to have poor availability of basic equipment.

\subsection{Statistical analysis}

Data were analyzed using SPSS version 25. Before running the full analysis, a test for multicollinearity was conducted as a means to ascertain the independence of independent variables from each other. These checks were followed by descriptive and inferential analyses. In the descriptive analysis, a total score for all items representing each variable was computed and set the cut-off score for variable categories. Each variable was then converted into a dichotomous variable. For example, the availability of tracer items (health facility staffing, essential medicines, and basic equipment) was transformed into "Good Availability" and "Poor Availability." The outcome variable of Access to MCH services was transformed into "Good Access" and "Poor Access." All categorical variables were summarized using proportions and then presented in tables. For the inferential analysis, logistic regression was applied to assess the association between health system variables (independent variables) and access to $\mathrm{MCH}$ services (dependent variable). Bivariate and multivariable regression models were fitted to assess the existence of the association between the dependent variable (access to MCH services) and the independent variables. Multiple linear regression was conducted to evaluate the relative strength of the predictor variables of type of health provider, level of health facility, availability of essential medicines, availability of basic equipment, type of health facility (private vs. public) with criterion variable of access to MCH services. Each of the predictor variables was inputted into the regression simultaneously to test which of the independent variables that had a statistically significant predictive relationship with the dependent variable; and a $p$-value $<.05$ significantly predicted access to MCH services.

\subsection{Ethics statement}

This study was based on an analysis of existing public domain survey data sets that are freely available online with all identifier information detached. The study had no direct interaction with study participants, as secondary data was used. Further, the participants in the SARA dataset are the 'health facilities,' and the data did not include personal identifiers. The survey was approved by the Ethics Committee of the ICF Macro at Calverton in the USA and by the Sierra Leone Ethics \& Scientific Review Committee (SLESRC). A data use agreement form was completed and submitted to the Ministry of Health \& Sanitation (MoHS) to use the data.

\subsection{Results}

\subsection{General characteristics of the surveyed facilities}

The distribution of the 1,284 health facilities by the level of health care delivery indicated that $1,174(91 \%)$ were PHUs, and 54 (4.2\%) and 56 (4.4\%) were hospitals and clinics respectively. The 1,174 PHUs were comprised of $625(53 \%)$ maternal and child health posts (MCHP), 325 (28\%) were community health posts (CHP), and 224 $(19 \%)$ were community health centers (CHCs). The distribution of the type of health facilities (public vs. private) showed that $1,037(81 \%)$ and $247(19 \%)$ were public and private, respectively.

\subsection{Health Facility and Access to MCH services}

Comparisons across both the level and type (private vs. public) of health facilities showed a significant difference in accessing $\mathrm{MCH}$ services (see Table 1).

Table 1: Access to MCH services across health facilities

Tracer indicators $\quad<50 \%$ (Poor $\quad \geq 50 \%$ (Good $\quad$ Chi $\quad$ df $\quad p$-value




\begin{tabular}{|c|c|c|c|c|c|}
\hline & Access) & Access) & & & \\
\hline & $\mathrm{n}(\%)$ & $\mathrm{n}(\%)$ & & & \\
\hline \multicolumn{6}{|l|}{ Level of health facility } \\
\hline Hospitals & $0(0)$ & $54(100)$ & & & \\
\hline Community health centers & $10(4.5)$ & $214(95.5)$ & 160.696 & 4 & $<.001$ \\
\hline Community health posts & $84(25.8)$ & $241(74.2)$ & & & \\
\hline Maternal \& child health posts & $281(45.0)$ & $344(55.0)$ & & & \\
\hline Clinic & $17(30.4)$ & $39(69.6)$ & & & \\
\hline \multicolumn{6}{|l|}{ Type of health facility } \\
\hline Public & $348(33.6)$ & $689(66.4)$ & 23.145 & 1 & $<.001$ \\
\hline Private & $44(17.8)$ & $203(82.2)$ & & & \\
\hline
\end{tabular}

3.3 Health Facilities and the availability of tracer items for MCH Services delivery

The availability of the tracer items for MCH service delivery (i.e., type of health provider, staffing, essential medicines, and basic equipment) varied across health facilities. As can be seen from tables 2 and 3 below, the type of health facility (private vs. public) and the level of health facility had a statistically significant association with access to MCH service provider $(p<.001)$. Regarding the availability of essential medicines, the type of health facility had a statistically significant association with essential medicines $(p<.001)$. However, the level of health facility showed no association with essential medicines $(p>.05)$. With regards the availability of basic equipment, the level of health facility showed a statistically significant association with basic equipment $(p<.001)$. The type of health facility (private vs. public) however, had no statistically significant association with basic equipment ( $p$ $>$.05).

Table 2: Level of health facility and availability of tracer items for MCH service delivery

\begin{tabular}{|c|c|c|c|c|c|}
\hline \multirow[t]{2}{*}{ Tracer indicators } & $\begin{array}{l}<50 \% \text { (Poor } \\
\text { Availability) }\end{array}$ & $\begin{array}{l}\geq 50 \% \quad \text { (Good } \\
\text { Availability) }\end{array}$ & \multirow[t]{2}{*}{ Chi } & \multirow[t]{2}{*}{ df } & \multirow[t]{2}{*}{$p$-value } \\
\hline & $\mathrm{n}(\%)$ & $(\%)$ & & & \\
\hline \multicolumn{6}{|l|}{ Availability of staffing } \\
\hline Hospitals & $1(1.9)$ & $53(98.1)$ & & & \\
\hline Community Health Centers & $16(7.1)$ & $208(92.9)$ & 436.181 & 4 & $<.001$ \\
\hline Community Health Posts & $164(50.4)$ & $161(49.6)$ & & & \\
\hline Maternal \& Child Health Posts & $502(80.3)$ & $123(19.7)$ & & & \\
\hline Clinic & $25(44.6)$ & $31(55.4)$ & & & \\
\hline \multicolumn{6}{|l|}{ Availability of Essential Medicines } \\
\hline Hospitals & $2(3.8)$ & $51(96.2)$ & & & \\
\hline Community Health Centers & $15(6.7)$ & $209(93.3)$ & & & \\
\hline Community Health Posts & $31(9.6)$ & $293(90.4)$ & 3.734 & 4 & $>.05$ \\
\hline Maternal \& Child Health Posts & $57(9.2)$ & $562(90.8)$ & & & \\
\hline Clinic & $3(6.0)$ & $47(94.0)$ & & & \\
\hline \multicolumn{6}{|l|}{ Availability of Basic Equipment } \\
\hline Hospitals & $0(0.0)$ & $54(100.0)$ & & & \\
\hline Community Health Centers & $0(0.0)$ & $224(100.0)$ & & & \\
\hline Community Health Posts & $8(2.5)$ & $317(97.5)$ & 21.173 & 4 & $<.001$ \\
\hline Maternal \& Child Health Posts & $11(1.8)$ & $614(98.2)$ & & & \\
\hline Clinic & $5(8.9)$ & $51(91.1)$ & & & \\
\hline
\end{tabular}


Table 3: Type of health facility and availability of tracer items for MCH service delivery

\begin{tabular}{|c|c|c|c|c|c|}
\hline \multirow{2}{*}{ Tracer indicators } & $<50 \%$ (Poor Availability) & $\geq 50 \%$ (Good Availability) & \multirow{2}{*}{ Chi } & \multirow{2}{*}{$\mathrm{df}$} & \multirow{2}{*}{$p$-value } \\
\hline & $\mathrm{n}(\%)$ & $\mathrm{n}(\%)$ & & & \\
\hline \multicolumn{6}{|c|}{ Availability of staffing } \\
\hline Public facilities & $619(59.7)$ & $418(40.3)$ & 45.142 & 1 & $<.001$ \\
\hline Private facilities & $89(36.0)$ & $158(64.0)$ & & & \\
\hline \multicolumn{6}{|c|}{ Availability of Essential Medicines } \\
\hline Public facilities & $103(10.1)$ & $921(89.9)$ & 16.422 & 1 & $<.001$ \\
\hline Private facilities & $5(2.0)$ & $241(98.0)$ & & & \\
\hline \multicolumn{6}{|c|}{ Availability of Basic Equipment } \\
\hline Public facilities & $22(2.1)$ & 1015(97.9) & 1.871 & 1 & $>.05$ \\
\hline Private facilities & $2(0.8)$ & $245(99.2)$ & & & \\
\hline
\end{tabular}

3.4 Association between the health system attributes and access to MCH services

A further analysis, using both bivariate and multivariate logistics regression was performed to examine any predictive relationship between health system attributes (i.e., type of health provider, level of health facility, availability of essential medicines, availability of basic equipment, and type of health facility) and access to $\mathrm{MCH}$ services. In the bivariate analysis, it was found that, all the 5 health systems attributes had a statistically significant association with access to $\mathrm{MCH}$ services and achieved a $p$-value $<.001$. This finding may suggest that health facilities with the right mix of health providers, and with available essential medicines and equipment can provide better access to $\mathrm{MCH}$ services. However, the results of the regression indicated that only 3 of the 5 predictors explained $38 \%$ of the variance $\left(R^{2}=.380, F(5,1263)=154.667, p<.001\right)$. It was found that the type of health provider significantly predicted access to $\mathrm{MCH}$ services $(\beta=.549, p<.001)$. The availability of both essential medicines $(\beta=.255, p<.001)$ and basic equipment $(\beta=.258, p<.001)$ also significantly predicted access to $\mathrm{MCH}$ services. Both the level (hospitals and PHUs) and type (private vs. public) of health facilities did not significantly predict access to $\mathrm{MCH}$ services $(p>.05)$. The output of the multivariate regression analysis indicates that the type of health provider, availability of essential medicines, and basic equipment are good predictors of access to $\mathrm{MCH}$ services in Sierra Leone.

\subsection{Discussions and Conclusions}

This study used a nationally representative data from the Sierra Leone 2017 SARA survey to examine the predictable relationship between 5 health system factors and access to MCH services.

1.Type of health provider and access to MCH services. The association between the available types of health provider and access to $\mathrm{MCH}$ services was examined. The results from bivariate and multivariate analyses showed a predictive relationship between the range of health providers (skilled birth attendants) and access to $\mathrm{MCH}$ services. Health facilities with the right mix of health providers have greater access to $\mathrm{MCH}$ services. This study supported the findings of numerous studies including Lawn et al. (2011), and Lassi et al. (2016) that the presence of certain critical resources including health professionals is a necessary ingredient in predicting access to $\mathrm{MCH}$ services. This can prevent most of the maternal deaths, stillbirths, and neonatal deaths. The findings from this study also supported evidence from related studies by Lawn, Tinker, Mujanja, and Cousens (2006), Ronsmans and Graham (2006), and Kinney et al., 2010 that demonstrated positive associations between access to facility-based services from skilled birth attendants during pregnancy, delivery and post delivery, and improved maternal health outcomes. A critical component of a functioning health system is the human resources for health. They are required in maintaining and improving population health.

2. Health infrastructure (Level and type of health facility) and access to MCH services. In examining the association between both the level (PHUs vs. hospitals) and type (public vs. private) of health facility and access to $\mathrm{MCH}$ services, it was found in the bivariate logistic regression analysis that access to $\mathrm{MCH}$ services varied by the level of care. This suggest that, the higher the level of care, the better the access to MCH services. Similarly, the results in the bivariate logistic regression analysis indicated a significant difference in access to $\mathrm{MCH}$ services by facility type (private vs. public). The private health facilities had better access to MCH services than public facilities. However, the association for both the level and type of health facility disappeared in the multivariate analysis, indicating that neither the level of health facility nor the type of health facility had a predictive relationship with access to MCH services. The findings of this study differed from Gebrehiwot, Sebastian, Edin, and Goicolea (2014)'s study on the health providers' perceptions of facilitators and barriers to the use of institutional delivery in Tigray, Ethiopia. Gebrehiwot et al. indicated that hospitals with specialized staff were a significant facilitator of facility-based delivery. Kruk et al. (2016) revealed that the quality of care in primary care facilities was substantially poorer than at secondary facilities. Shayo et al. (2015) compared the access and use of quality, equity, and trust in the Mbarali district and revealed contrary findings to this study. Shayo et al. reported that respondents who visited public health facilities reported medicine shortages more than those who visited 
nonpublic health facilities. The variance between the findings of the current study and many others can be explained by the level of interventions and diagnostic procedures examined in the current study. Only the minimum $\mathrm{MCH}$ tracer items that can be found across all health facilities as prescribed in the Sierra Leone BPEHS were considered, and not the advanced diagnostic equipment and medicines found in secondary and tertiary hospitals. 3.Availability of essential medical commodities and access to MCH services. The association between the availability of essential medical commodities (i.e., essential medicines and basic equipment) and access to $\mathrm{MCH}$ services was also examined. The results from bivariate and multivariate analyses showed a predictive relationship between the availability of both essential medicines and basic equipment, and access to MCH services. Health facilities with better supplies of essential medicines had greater access to MCH services. Similarly, health facilities with better supplies and functioning equipment had greater access to $\mathrm{MCH}$ services. The findings of the current study were in concurrence with studies that demonstrated an association between medical commodities and access to quality maternal health care. The absence of sufficient medical commodities, such as medicine and equipment, will hamper the provision of services, undermine the quality of care, and lead to low levels of patients' satisfaction and preventable deaths (Mkoka et al., 2014; Penfold et al., 2013). Sumankuuro, Crockett, and Wang (2018) showed significant barriers affecting the quality and appropriateness of maternal and newborn health services. Among the notable obstacles, they noted were inadequate medical equipment and essential medicines

In summary, this study indicates that Sierra Leone, like many other low-income countries, faces chronic health system challenges that limits access to maternal and child health. The persisting high maternal and child mortalities in these countries testify the prevailing social injustice in the access to quality $\mathrm{MCH}$ services for disadvantaged populations. This study has provided insight on the important role of staffing, essential medicines, and basic equipment on accessing MCH services. In Sierra Leone, the ANC attendance rates by pregnant women as well as the uptake of childhood immunization, for example, are impressively high. The current study has however revealed that there is a significant difference in the availability of $\mathrm{MCH}$ tracer indicators of staffing, essential medicines, and basic equipment in all health facilities regardless of the level of care and type of facilities (private vs. public). In order to improve access to $\mathrm{MCH}$ services, the health system leaders should implement strategies to better ensure fair distribution of skilled birth attendants, essential medicine, and equipment in all every health facility. The study also showed that both the level of care and the type of health facilities do not influence access to MCH services. Little is known in Sierra Leone on the extent to which the numerous health facilities in the country drive demand for $\mathrm{MCH}$ services. Therefore, further research could help understand the drivers of $\mathrm{MCH}$ utilization. In particular, qualitative studies will be helpful to provide an in-depth understanding of the intricate dynamics of access to MCH services. It is important to also note that, accessing MCH services is not sufficient to assure quality. Further qualitative and quantitative research on the quality of $\mathrm{MCH}$ services provided in health facilities is therefore also needed. These studies should investigate barriers to quality $\mathrm{MCH}$ services provision and maternal, and child health outcomes to guide the design of public health interventions aim at improving the quality as well as increasing access to $\mathrm{MCH}$ services.

\subsection{Policy Implications}

This study may play an important role in designing effective interventions for improving the accessibility of quality $\mathrm{MCH}$ services. Its findings have highlighted three important areas of consideration for a functioning health system: health provider, essential medicines, and basic equipment as critical tracer items for the delivery of $\mathrm{MCH}$ services. Sierra Leone, like many other countries in sub-Saharan Africa, faces serious challenges on the needed human resources for a responsive health system due to the chronic shortage of staff and coupled with mal-distribution with urban/rural disparity. This inherently undermines the quality of service delivery. The MoHS should, therefore, put in place a human resource policy that encourages the training and equitable distribution of staff, especially skilled birth attendants across the country. The collective efforts of both MoHS and its development partners should also be directed towards providing incentives (housing, remote allowances, professional development among others) to enhance staff retention, especially for those in hard-to-reach communities to reduce the inequities in the access to $\mathrm{MCH}$ services.

Frequent stock-outs of essential medicines in health facilities have the propensity of driving MCH serviceusers away from the health facilities to private health providers, for example. As a result of high costs of treatment in private health facilities, the implications for users would include delay in seeking care and sub-optimal treatment for conditions; leading to further complications and sometimes death. The availability of essential medicines as well as basic equipment must, therefore, be prioritized by ministries of health to maximize the impact of the health system on population health outcomes. Often, governments find it difficult to manage the procurement and distributions of medical commodities, which leads to the delay in replenishing stock. Private-public-partnership (PPP) could be an effective approach in overcoming such challenges with resultant improvement on access to MCH services. With global concerns over the shrinking support for public health programs, donor-dependent health systems like the one in Sierra Leone can use the findings of this study to prioritize health sector investment and galvanizing relevant individuals and agencies in the private sector for robust mobilization and effective and 
efficient management of health sector resources.

\subsection{Study Limitations}

This study is the first to examine the predictive relationship between health system characteristics and access to $\mathrm{MCH}$ services in Sierra Leone. The strength of the current study is that it analysed a nationally-representative sample of health facilities in Sierra Leone, providing key insight into health system influence on access to MCH services. However, this study had some limitations. Firstly, the cross-sectional nature of the study did not allow any sequencing of events between predictor variables and the criterion nor any trend analysis on the outcome of the study. Secondly, the study did not collect household data to understand other barriers to accessing $\mathrm{MCH}$ services. At the household level, a range of different measures of equity (e.g. geographical location of health facility; traveling time to health facility; direct and indirect cost of services) and socioeconomic status (e.g. education, age, employment staus) have been considered as significant predictors to healthcare access (Ruktanochai et al., 2016; Weitzman, 2017 ). The demand-side factors of accessing MCH services are, therefore missed out in this study. Lastly, the study is subjected to misclassification bias due to the use of arbitrary cut-off point set at 50\%; this might be misclassified access of health facilities to provide MCH services. The inclusion of many indicators as suggested by the WHO SARA questionnaire to assess service availability and readiness of health facilities might have minimized this bias.

\subsection{References}

Bertone, M. P., Samai, M., Edem-Hotah, J., \& Witter, S. (2014). A window of opportunity for reform in postconflict settings?. The case of human resources for health policies in Sierra Leone, 2002-2012. Conflict and Health, 8, 11-23. doi:10.1186/1752-1505-8-11

Bintabara, D., \& Mpondo, B.C.T. (2018). Preparedness of lower-level health facilities and the associated factors for the outpatient primary care of hypertension: Evidence from a Tanzanian national survey. PLoS ONE, 13(2), 1-14. doi:10.1371/journal.pone.0192942

Bintabara, D., Nakamura, K., \& Seino, K., (2017). Determinants of facility readiness for the integration of family planning with HIV testing and counseling services: Evidence from the Tanzania service provision assessment survey, 2014-2015. BMC Health Services Research, 17, 844. doi:10.1186/s12913-017-2809-8

Demographic Health Survey [DHS] (2013). Sierra Leone demographic health survey 2013. Retrieved from: https://dhsprogram.com/pubs/pdf/FR297/FR297.pdf

Elston, J.W.T., Moosa, A.J., Moses, F., Walker, G., Dotta, N., Waldman, R.J., \& Wright, J. (2015). Impact of the Ebola outbreak on health systems and population health in Sierra Leone. Journal of Public Health, 38(4), 673-678. doi:10.1093/pubmed/fdv158

Gebrehiwot, T., Sebastian, M.S., Edin, K., \& Goicolea, I. (2014). Health workers' perceptions of facilitators and barriers to institutional delivery in Tigray, Northern Ethiopia. BMC Pregnancy and Childbirth, 14(137), 110. doi:10.1186/1471-2393-14-137

Government of Sierra Leone [GoSL] (2013). Millennium development goals progress report 2013. Retrieved http://www.undp.org/content/dam/undp/library/MDG/english/MDG\%20Country\%20Reports/Sierra\%20Leo ne/sierraleone_september2010.pdf

Kinney, M.V., Kerber, K.J., Black, R.E., Cohen, B., Nkrumah, F., Coovadia, H., . . Lawn, J. (2010). Sub-Saharan Africa's mothers, newborns, and children: Where and why do they die?. PLoS Medicine, 7(6), 1-9. doi:10.1371/ journal.pmed.1000294

Kruk, M. E., Leslie, H. H., Verguet, S., Mbaruku, G. M., Adanu, R. M. K., \& Langer, A. (2016). Quality of basic maternal care functions in health facilities of five African countries: An analysis of national health system surveys. Lancet Glob Health, 4, e845-855. doi:10.1016/S2214-109X(16)30180-2.

Lassi, Z.S., Musavi, N.B., Maliqi, B., Mansoor, N., de Francisco, A., Toure, K., \& Bhutta, Z.A. (2016). Systematic review on human resources for health interventions to improve maternal health outcomes: Evidence from low- and middle-income countries. Human Resources for Health, 14 (10), 1-20. doi: 10.1186/s12960-0160106-y

Lawn, J.E., Blencowe, H., Pattinson, R., Cousens, S., Kumar, R., Ibiebele, I., . . Stanton, C. (2011). Stillbirths: Where? When? Why? How to make the data count?. The Lancet, 377, 1448-1463. doi:10.1016/S01406736(10)62187-3

Lawn, J. E., Tinker, A., Munjanja, S. P, \& Cousens, S. (2006). Where is maternal and child health now?. Lancet, 368 (9546), 1474-1477. doi: 10.1016/S0140-6736(06)69387-2

Mkoka, D.A., Goicolea, I., Kiwara, A., Mwangu, M., \& Hurtig, A. K. (2014). Availability of drugs and medical supplies for emergency obstetric care: Experience of health facility managers in a rural District of Tanzania. BMC Pregnancy Childbirth, 14(108), 1-10. doi:10.1186/1471-2393-14-108

Ministry of Health \& Sanitation [MoHS] (2015). Health sector recovery plan (2015-2020). Ministry of Health \& Sanitation, Sierra Leone. Retrieved from: https://mohs2017.files.wordpress.com/2017/06/health-sector- 
recovery-plan-2015-2020.docx

Penfold, S., Shamba, D., Hanson, C., Jaribu, J., Manzi, F., Marchant, T., . . . Scellenberg, J. A. (2013). Staff experiences of providing maternity services in rural southern Tanzania- a focus on equipment, drug, and supply issues. BMC Health Services Research, 13(61), 1-9. doi:10.1186/1472-6963-13-61

Ribacke, K. J. B., van Duinen, A. J., Nordenstedt, H., Höijer, J., Molnes, R., Froseth, W., . . AnnaMia, E. (2016). The impact of the West Africa Ebola outbreak on obstetric health care in Sierra Leone. PLoS ONE 11(2): e0150080. doi:10.1371/journal.pone.0150080

Ronsmans, C., \& Graham, W.J. (2006). Maternal mortality: Who, when, where, and why. Lancet, 368 (9542), 1189-1200. doi:10.1016/S0140-6736(06)69380-X

Ruktanonchai, C.W., Ruktanonchai, N.W., Nove, A., Lopes, S., Pezzulo, C., Bosco, C., . . Tatem, A. J. (2016). Equality in maternal and newborn health: Modelling geographic disparities in utilization of care in five East African countries. PLoS ONE, 11(8), 1-17. doi:10.1371/journal.pone.0162006

Shayo, E. H., Senkoro, K. P., Momburi, R., Olsen, O. E., Byskov, J. Makundi, E. A., . . Mboera, L. E. G. (2015). Access and utilization of healthcare services in rural Tanzania: A comparison of public and non-public facilities using quality, equity, and trust dimensions. Global Public Health, 11 (4), 407-422. doi: $10.1080 / 17441692.2015 .1132750$

Stekelenburg, J., Kyanamina, S., Mukelabai, M., Wolffers, I., \& van Roosmalen, J. (2004). Waiting too long: Low use of maternal health services in Kalabo, Zambia. Tropical Medicine \& International Health, 9(3), 390-398. doi:10.1111/j.1365-3156.2004.01202.x

Sumankuuro, J., Crockett, J., \& Wang, S. (2018). Perceived barriers to maternal and newborn health services delivery: A qualitative study of health workers and community members in low and middle-income settings. BMJ Open, 8,e021223. doi:10.1136/bmjopen-2017-021223

Thaddeus, S., \& Maine, D. (1994). Too far to walk: Maternal mortality in context. Social Science \& Medicine, 38(8), 1091-110. doi:10.1016/0277-9536(94)90226-7

Tlebere, P., Jackson, D., Loveday, M., Matizirofa, L., Mbombo, N., Doherty, T., . . . Chopra, M. (2007). Community-based situation analysis of maternal and neonatal care in South Africa to explore factors that impact utilization of maternal health services. Journal of Midwifery \& Women's Health, 52(4), 342-350. doi:10.1016/j.jmwh.2007.03.016

Tran, T. K., Gottvall, K., Nguyen, H. D., Ascher, H., \& Petzold, M. (2012). Factors associated with antenatal care adequacy in rural and urban contexts-results from two health and demographic surveillance sites in Vietnam. BMC Health Services Research, 12(1), 40-49. doi:10.1186/1472-6963-12-40

Trinh, L., Dibley, M., \& Byles, J. (2007). Determinants of antenatal care utilization in three rural areas of Vietnam. Public Health Nursing, 24(4), 300-310. doi: 10.1111/j.1525-1446.2007.00638.x

United Nations (2015). The Millennium Development Goals Report, 2015. New York, United Nations. Retrieved from: http://www.un.org/millenniumgoals/2015_MDG_Report/pdf/MDG\%202015\%20rev\%20(July\%201).pdf

United Nations (2016). Sustainable Development Goals. New York: United Nations. Retrieved from: http://www.un.org/ sustainabledevelopment/sustainable-development-goals/

Weitzman, A. (2017). The effects of women's education on maternal health: Evidence from Peru. Social Science \& Medicine, 180,1-9. doi:10.1016/j.socscimed.2017.03.004

Witter, S., Brikci, N., Harris, T., Williams, R., Keen, S., Mujica, A., . . Renner, A. (2018). The free healthcare initiative in Sierra Leone: Evaluating a health system reform, 2010-2015. International Journal of Health Planning \& Management, 1-15. doi:10.1002/hpm.2484

World Health Organization [WHO] (2011a). The Abuja Declaration: Ten years on. Retrieved from http://www.who.int/healthsystems/publications/abuja_report_aug_2011.pdf

World Health Organization [WHO] (2011b). Health system strengthening - Current trends and challenges. Executive Board 128th Session, Geneva, 17-25 January 2011," January 17, 2011, Retrieved from: http://apps.who.int/gb/ebwha/pdf_files/EB128/B128_37-en.pdf.

World Health Organization [WHO] \& UNICEF (2014a). UNFPA, The World Bank, \& the United Nations Population Division. (1999). Trends in Maternal Mortality: 1990-2013. Estimates by WHO, UNICEF, UNFPA, The World Bank, and the United Nations Population Division. Retrieved from: https://www.who.int/reproductivehealth/publications/monitoring/maternal-mortality-2013/en/

World Health Organization [WHO] (2014b). Maternal mortality fact sheet 2014. Retrieved from: http://www.who.int/mediacentre/fact-sheets/fs348/en/. 